\title{
Mitigation of incidental mortality of Australian sea lions in the west coast rock lobster fishery
}

\author{
Richard Campbell ${ }^{1, *}$, David Holley ${ }^{1}$, Dimitrios Christianopoulos ${ }^{1}$, Nick Caputi ${ }^{1}$, \\ Nicholas Gales ${ }^{2}$
}

${ }^{1}$ Western Australian Fisheries and Marine Research Laboratories, Dept. of Fisheries PO Box 20, North Beach 6920, Australia

${ }^{2}$ Australian Antarctic Division, Channel Hwy, Kingston 7050, Australia

\begin{abstract}
The Australian sea lion is a listed threatened species under Australian Commonwealth legislation, based on limited population size and the likelihood of further declines in population abundance. Incidental mortality of this species in the west coast rock lobster fishery was identified as a key threat to the distinct sub-population of about 700 ind. on the west coast of Australia. Reports of incidental mortalities in this fishery from a variety of fishery-dependent sources suggested that a minimum of 4 to 5 mortalities occur every fishing season. All reported captures were in shallow waters $(<20 \mathrm{~m})$ and within $30 \mathrm{~km}$ of a breeding colony. Foraging ranges of vulnerable-sized animals were confirmed by use of satellite-linked transmitters and time-depth recorders. Mitigation of this incidental mortality was effected by means of modifying the lobster pots with a sea lion exclusion device within the area of known interaction. The mandatory implementation of this programme resulted in a very high compliance rate $(95 \%)$ in the first season and was achieved through active consultation and involvement of the industry, and of fishery and wildlife managers.
\end{abstract}

KEY WORDS: Australian sea lion · Western rock lobster fishery $\cdot$ Neophoca cinerea $\cdot$ Mitigation of bycatch $\cdot$ Commercial fishing $\cdot$ Sea lion exclusion

Resale or republication not permitted without written consent of the publisher

\section{INTRODUCTION}

The Australian sea lion (ASL) Neophoca cinerea is Australia's only endemic pinniped species, and current population estimates of 10000 to 12000 make it one of the rarest sea lions in the world (Gales et al. 1994, Goldsworthy et al. 2003). This species is currently listed as threatened ('vulnerable' category) under Australian Commonwealth legislation (Environmental Protection and Biodiversity Conservation Act 1999, EPBC Act), partly based on the premise that population declines are likely to continue. Its breeding range extends from the Houtman Abrolhos Islands $\left(28.45^{\circ} \mathrm{S}\right.$, $113.75^{\circ} \mathrm{E}$ ) on the west coast of Western Australia to The Pages, in South Australia (35.77 $\left.\mathrm{S} 138.3^{\circ} \mathrm{E}\right)$. There are over 70 individual breeding colonies, predominantly on offshore islands, most of which produce less than 50 pups every breeding season (Shaughnessy 1999). Regional extirpations of this species occurred over $150 \mathrm{yr}$ ago due to commercial harvesting, but there has been no subsequent recolonisation (Gales et al. 1994, Ling 1999).
This species displays unique breeding biology, having a supra-annual, asynchronous breeding cycle across its range (Ling \& Walker 1978, Higgins 1993, Gales et al. 1994). This differs from the usual annual, synchronous breeding cycles of all other pinnipeds, excepting the walrus (Boyd 1991). The consequences of this unusual breeding behaviour on the population genetic structure are profound. Females display an extremely high level of natal site fidelity, such that recruitment of females is almost exclusively from within each breeding colony (Campbell et al. 2008). This has important implications for the conservation management of this species, as virtually every breeding colony becomes a management unit (see Moritz 1994).

The west coast of Western Australia supports a small population of approximately 700 to 800 ASLs (Gales et al. 1994). There are 4 breeding colonies and a number of key haulout (non-breeding) sites along this coast, and their distribution overlaps with the west coast rock lobster fishery (WCRLF; Fig. 1). Pup production at 
these colonies has been relatively stable over the past $15 \mathrm{yr}$, although the colonies are small, isolated populations of locally recruiting females (see Fig. 1 legend for mean values; McKenzie et al. 2005, Campbell et al. 2008). Small, isolated populations of this species are susceptible to low levels of chronic incidental mortality (Goldsworthy \& Page 2007), and mitigation of key threatening processes is a fundamental part of the draft federal recovery plan for this species (McKenzie et al. 2005).

Bycatch of pinnipeds in commercial fishing operations occurs worldwide (Reijnders et al. 1993) and may increase the extinction risk of already vulnerable species (Woodley \& Lavigne 1993). Incidental bycatch of the ASL in rock lobster fisheries has been reported throughout its range in Australia (Shaughnessy et al. 2003) and more specifically in Western Australia (Mawson \& Coughran 1999). Tagging studies on ASL on the west coast of Western Australia suggested that '...a significant proportion of pups from one colony had

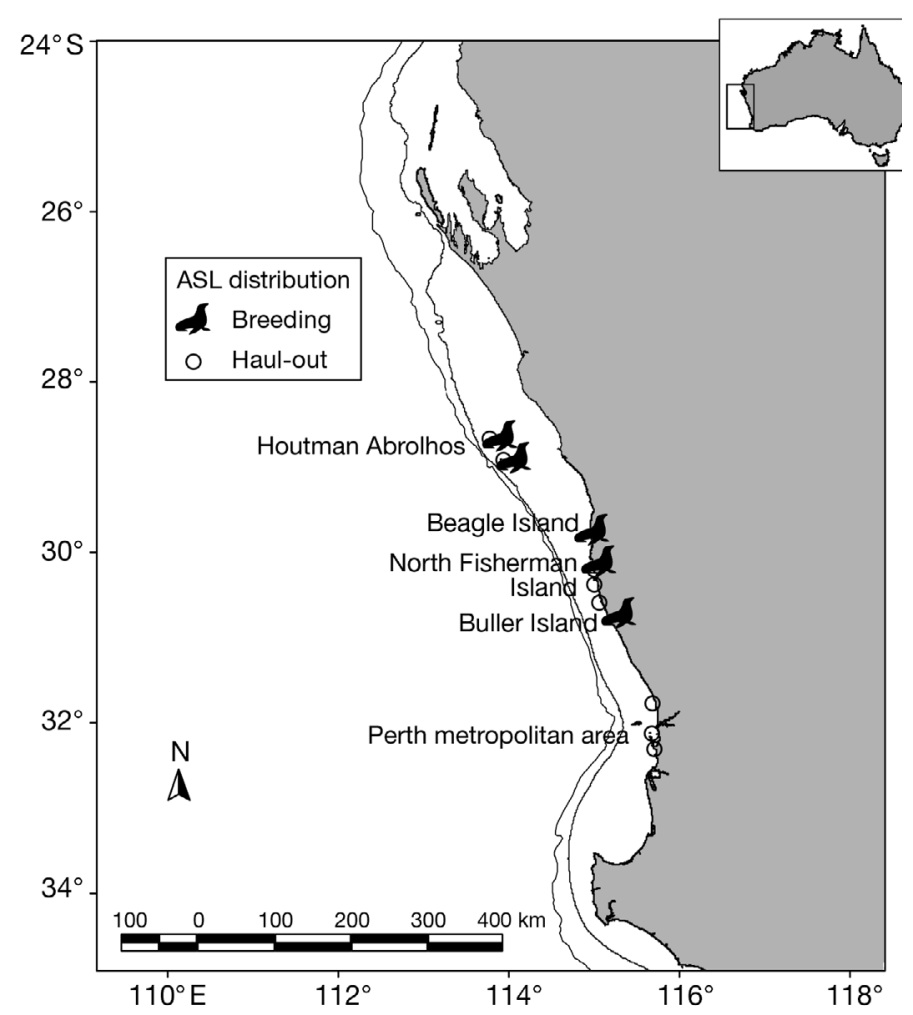

Fig. 1. Distribution of breeding colonies and major haulout areas of the Australian sea lion (ASL) in the area covered by the west coast rock lobster fishery in Western Australia. The northern and southern extents of the fishery are defined by the map borders, and the continental shelf edge $(100$ to $200 \mathrm{~m})$, indicated by the black lines, defines the seaward extent of the fishery. Mean pup production values for these breeding colonies are as follows: Houtman Abrolhos, 18; Beagle Island, 65; North Fisherman Island, 49; Buller Island, 39 drowned in crayfish pots' (Gales et al. 1994, p. 367). It is believed that sea lions enter through the neck of the pot and occasionally get caught and drown. The WCRLF operates seasonally from November to June and is a pot-based fishery with restrictions on the dimensions of the pots used. The neck or entry of the pot may be no smaller than $160 \mathrm{~mm}$ diameter for circular entrances and have a side of no less than $160 \mathrm{~mm}$ for square or rectangular entrances with no restriction on the maximum dimension allowed (Fish Resources Management Act 1984).

This fishery was the first in the world to be accredited as ecologically sustainable by the Marine Stewardship Council (MSC, see www.msc.org for more details), which included assessment of the impact on protected species. From a preliminary assessment of the bycatch data and based on the dimensions of the lobster pots, it was thought that only the pup and juvenile age classes were vulnerable to capture (Anonymous 2001). Based on the biology of the ASL and the limited knowledge of the interaction with the rock lobster fishery, it was determined that this represented a moderate ecological risk to the viability of the sea lion population (International Risk Consultants 2001). This assessment required a considered management response, which through the formation of an independent sea lion scientific reference group (SLSRG) recommended that the incidental mortality be eliminated by modifying the pots to restrict the entry of sea lions (Department of Fisheries 2003).

Here, we outline the process taken to determine the extent of the interaction issue, discuss the threat analysis to the population, and evaluate the development and implementation of mitigation strategies to address the issue of incidental mortality. Our evaluation follows a 3 step process: (1) we determine the rate, spatial and temporal characteristics and impact of this incidental mortality on the viability of sea lion populations; (2) we discuss the design of effective sea lion exclusion devices (SLEDs) that preclude the entry of sea lions into pots, but do not affect catch rates of the target species (rock lobster) and can be fitted to all types of pots used in the fishery; and (3) we present research on the foraging behaviour of vulnerable-sized sea lions to corroborate with fishery-dependent data on the locations of interactions to determine the extent of a mandatory zone in which to recommend the use of SLEDs.

\section{MATERIALS AND METHODS}

Characteristics of interaction and risk assessment. Rates of incidental capture: Characteristics of the interaction between ASLs and the WCRLF were gauged from 4 fishery-dependent sources: an annual 
bycatch survey, voluntary logbook returns, a targeted telephone survey of commercial fishers and the total number of incidents reported to the Department of Fisheries (DOF). Data provided included the year, time and place of capture and any information about the captured animal. In many cases, the specific time and place of capture and biological information were not provided due to the time lapse between the incident and the reporting of the event.

Two voluntary forms of data are routinely collected by the DOF for each fishing season. The annual survey form was sent to all commercial fishermen throughout the state at the end of each fishing season asking for information on fishing activity and interactions with protected species. This survey has been in operation since the 1999 to 2000 fishing season and has a compliance rate of approximately 30 to $35 \%$ each season. The survey does not distinguish between different areas of the WCRLF. A voluntary daily logbook programme in the WCRLF, which records rock lobster catch and effort data, began reporting interactions with protected species during the 2000 to 2001 fishing season. Approximately one-third of the commercial fleet participated in this programme over the course of the study. Rock lobster fishermen who reported any interaction with sea lions in the aforementioned forms were contacted to record specific details of the event(s) (i.e. location, depth, size of animal, etc.) if not already provided. Additionally, incidental mortalities would be reported to the DOF independent of the 2 aforementioned surveys and all information regarding the interaction was recorded.

For the purposes of this study, an initial phone survey of 67 randomly chosen rock lobster fishermen from the total fleet of 563 boat operators in 2002 and 2003 was conducted to record their history of interaction with ASLs over the course of their involvement in the WCRLF. This survey covered approximately $20 \mathrm{yr}$ of fishing, recording interactions back as far as the 1980 to 1981 fishing season. A preliminary analysis of the spatial distribution of interactions with sea lions from the 2 voluntary programmes (annual survey and volunteer logbook) and the initial phone survey suggested that interactions occurred exclusively in an area on the mid-west coast in proximity to 3 known ASL breeding colonies (see Fig. 2). A targeted phone survey of an additional 61 commercial fishermen in this area, representing approximately $40 \%$ of this fleet based on DOF anchorage lists, was conducted to gain a more accurate estimate of the historical rate and spatial distribution of interaction.

Estimates of the total number of incidental captures per fishing season were calculated from each of these datasets. The compliance rate of the annual survey for each season was used to extrapolate the rate of reported captures to an estimate for each fishing season over the whole fishery. This method was on the coarse level of the whole fishery and this may result in an underestimate of the rate of incidental capture.

The number of incidental captures of sea lions reported in the volunteer logbook programme was extrapolated to a total figure by estimating the proportion of fishing effort undertaken by the volunteer logbook participants relative to total fishing effort for each

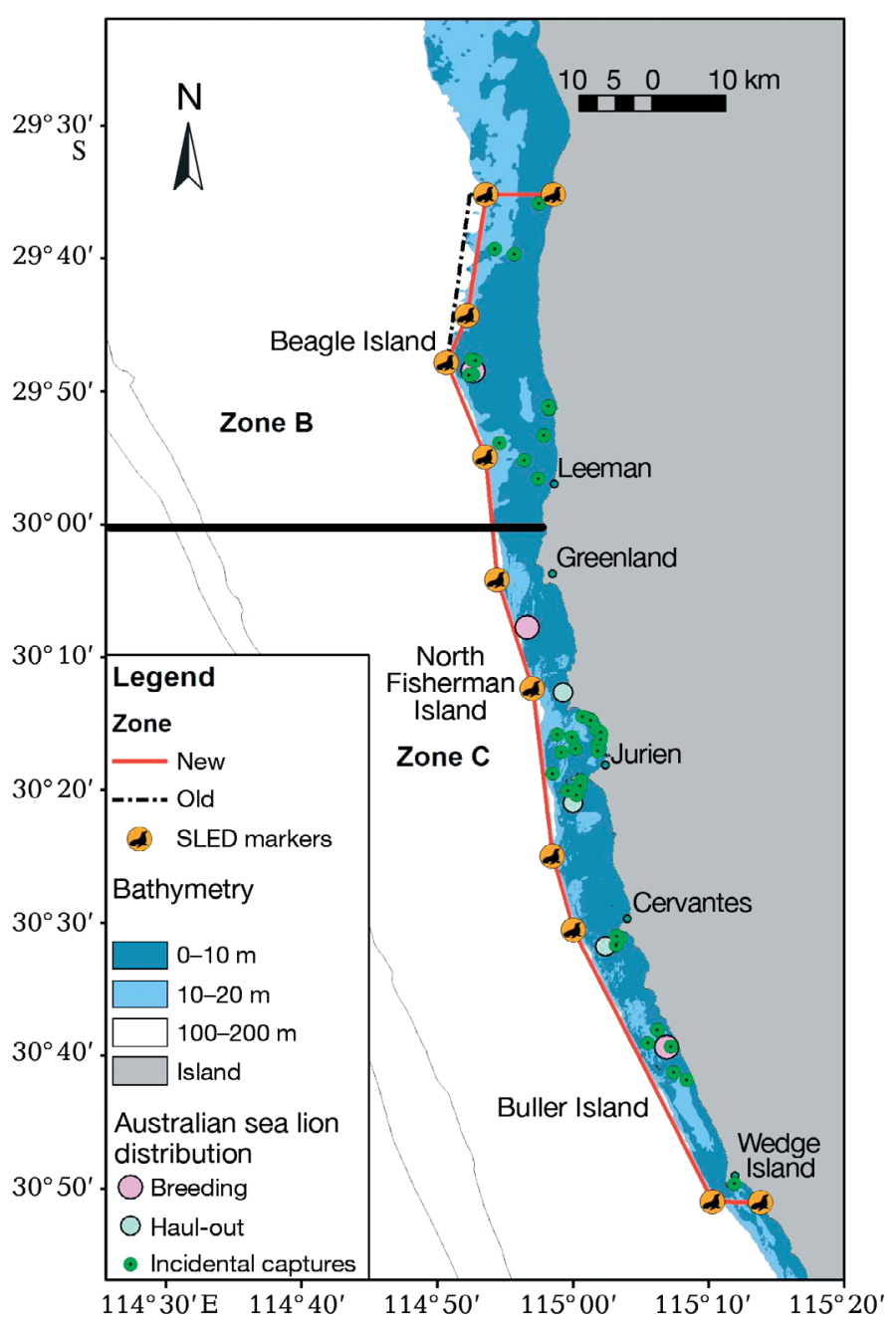

Fig. 2. Location of reported incidental captures of Australian sea lions in the west coast rock lobster fishery relative to the breeding colonies and haulout locations of the central west coast. The majority of captures occurred in 0 to $10 \mathrm{~m}$ and all were in waters $<20 \mathrm{~m}$. Captures were recorded a maximum of $30 \mathrm{~km}$ from the nearest breeding colony, indicating a maximum dispersal of approximately $30 \mathrm{~km}$ for vulnerable-sized sea lions. A proposed area for the mandatory use of sea lion exclusion devices (SLEDs, - ) was designed to encompass the distribution of the reported incidental captures. Dasheddotted line: area in which the use of SLEDs is currently mandatory. Thin grey lines: continental shelf edge; thick black line: division between Fishery Management Zones B and C 
season within the defined area of interaction between sea lions and the fishery. For this calculation, the total fishing effort in the area of interaction and depth category $(0$ to $20 \mathrm{~m})$ was calculated using a combination of the compulsory monthly fishing effort returns (CAES) and information provided by the voluntary logbook programme for each season separately. Fishing effort recorded in the CAES system is on a scale of $1 \times$ 1 degree $(60 \times 60$ nautical miles, $\mathrm{n}$ miles $)$. This is refined by breaking down each block into $10 \mathrm{~min}$ ( $6 \mathrm{n}$ miles or $10 \mathrm{~km}$ ) grids by latitude, based on information from the logbook programme participants about their proportion of fishing effort within each $10 \mathrm{~km}$ block. This involved measuring the total effort (number of pot lifts) of the fleet in the pre-determined area of interaction and then using the breakdown of fishing effort by depth in this area to determine the proportion of fishing effort in each 10 min block. Fishing effort within each 10 min block was further broken down into 2 depth categories, $<20$ and $>20 \mathrm{~m}$, using the same technique. These calculations assume that all fishers had the same probability of catching a sea lion, that fishers participated in the annual survey and logbook programme independent of their level of interaction with sea lions and that fishing practices of the logbook programme participants are representative of the fishing fleet in the area of interest.

The targeted phone survey of 61 fishermen in the defined interaction area collected information on their history of interactions with sea lions for the period 1980/1981 to 2003/2004, and their nominal fishing effort (number of vessel fishing seasons) during this time. From these data, a rate of captures per vessel fishing season was calculated and was extrapolated to an estimated capture rate of sea lions per fishing season (for 1999/2000 to 2003/2004) based on the number of vessels operating in the defined area of interaction as determined from DOF anchorage lists. This method resulted in a relatively uniform estimate of incidental capture rate per fishing season due to the relatively constant number of boats at each anchorage in the defined area of interaction.

It must be remembered that all of these estimates are based on fishery-dependent information and that commercial fishing responses sometimes underestimate the rate of interaction with protected species. In view of this, the estimates provided in this study should be considered as minimum estimates of the incidental mortality rate.

Spatial and temporal patterns of interaction: Locations of the reported incidental captures of ASLs were mapped relative to the breeding colonies and haulout sites using the ArcGIS v9 package (ESRI 2004). Estimates of minimum dispersal distance of animals from their most likely natal site were determined by calculating straight-line-at-sea distances between the location of capture and the nearest breeding colony. The locations of breeding colonies were taken from Gales et al. (1994).

The likely age (mo) of the incidentally captured animals with known capture dates was estimated by using the median date of the last breeding season as the birth date of the captured animal $( \pm 2.5 \mathrm{mo}$, to take into account the 4 to 5 mo length of the breeding season for west coast colonies, Gales et al. 1992). Timing of the breeding seasons was extrapolated from Gales et al. (1994) with slight corrections from observations over the last $10 \mathrm{yr}$ (R. Campbell unpubl. data). Animals that were calculated to be less than 5 mo old were reclassified as being born in the preceding breeding season, as ASL pups are restricted to their birth colony and the very nearshore waters until approximately 4 to 5 mo of age (Gales et al. 1992). Young animals of this age are restricted to surface splashing when in the water and do not exhibit benthic diving behaviour (Fowler et al. 2006) and so are thought not to be vulnerable to capture in lobster pots. It is acknowledged that determining a minimum age at which pups become vulnerable to capture is difficult and may not reflect the variation in the onset of foraging and vulnerability to capture.

Population viability analysis (PVA). PVA of the 3 breeding colonies was performed using a stable agestructured model of ASLs based on data from other species (see Goldsworthy \& Page 2007 for polynomial functions of survival). Based on the extreme genetic subdivision of ASL colonies (Campbell et al. 2008), each colony was modelled as a separate management unit. No density-dependent effects were incorporated, as contemporary population densities are believed to be well below pristine levels (Campbell 2005) and densitydependent effects are unlikely to be operating (Goldsworthy \& Page 2007). Two scenarios of population trajectory were simulated, one of a stable population $(r=0)$ and the other of a population growing at approximately $2 \%$ per breeding cycle $(\mathrm{r}=0.019)$, established by increasing rates of survival across all age groups. The stable population scenario simulates the current population trend (R. Campbell unpubl. data), and the increasing $(2 \%)$ population trajectory is a hypothetical scenario based on values observed at other ASL colonies (McKenzie et al. 2005, Goldsworthy \& Page 2007).

Harvest rates of 1 to 4 female juvenile animals per breeding cycle were simulated over 100 breeding cycles using 500 iterations for both the population trajectory scenarios in the computer package Vortex 9.70 (Lacy et al. 2006). Outputs included the probability of extinction for each step and the finite population growth rate (r) at the completion of each simulation.

The 'threatened' species classifications of Mace \& Lande (1991), with slight modification, were used to 
determine the status of each colony for both population trajectories under the range of harvest scenarios. These were 'vulnerable,' with a $10 \%$ probability of extinction within 100 breeding cycles (current EPBC Act status of the species); 'endangered,' with a $20 \%$ probability of extinction within 80 breeding cycles; 'critically endangered,' with a $50 \%$ probability of extinction within approximately 20 breeding cycles; and 'extinct,' with a $100 \%$ probability of extinction or quasi extinction. Extinction was defined as being the point at which no breeding females were left. The default status of each management unit was vulnerable based on the current classification of this species under the EPBC Act (1999). The probability of extinction was used to classify each colony for each harvest scenario for both population trajectories (stable and increasing) to determine what impact the levels of fishing-related mortality may have on the viability and conservation status of these colonies. Based on these definitions, simulations met with the criteria for critically endangered and extinct under the same conditions in virtually the same timeframe; hence, these 2 classifications were grouped.

The harvest rates per colony $\left(M_{\mathrm{H}}\right)$ per breeding cycle used in the PVA simulations were converted to an equivalent total number of sea lion captures per fishing season $\left(M_{\mathrm{FS}}\right)$ based on the following equation:

$$
M_{\mathrm{FS}}=M_{\mathrm{H}} \times 2 \times 3 / 1.5
$$

where $M_{\mathrm{FS}}$ was derived by assuming that male and female sea lions were captured at the same rate $(\times 2)$ and that capture of animals from all 3 colonies occurred at the same rate $(\times 3)$. This provided an estimate of incidental capture rate per breeding cycle ( 18 mo), which was converted to an annual figure by dividing by 1.5 .

SLED evaluation. Efficacy of devices and behavioural interaction between ASLs and lobster pots: A suitable SLED had to create a minimum size passage through the neck of the pot (SLED-neck gap), which precluded the entry of sea lions but still allowed the entry of the target species (rock lobster). Consultation with commercial fishers, pot designers and gear technologists resulted in 2 designs being chosen. SLED A consisted of a steel rod pointing upward from the base of the pot toward the pot opening and SLED B was composed of a batten or stiff rod placed across the opening of the pot (Fig. 3a,b). SLED A is a variation on an idea used by some rock lobster fishers in South Australia to deter sea lions from robbing bait from pots (Anonymous 1996).

Experiments to examine the efficacy of the SLED designs were conducted by observing and recording the in-water interaction between ASLs and lobster pots. A control pot (no SLED) and one fitted with a SLED were set in shallow water adjacent to the North Fisherman Island breeding colony (Fig. 2). Redneck batten pots were used in the trials, as they are the most commonly used pot in this part of the fishery.

Each pot was seeded with a number of lobsters (10 to 15) to act as an enticement for the sea lions to enter. Trials for each SLED treatment ran until all lobsters were removed from either pot or until sea lions lost interest and moved away from the experimental area. Four SLED A treatments were conducted, with the height of the steel rod varying from flush $(0 \mathrm{~mm})$ with the neck, to 20, 40 and $60 \mathrm{~mm}$ below, respectively. A single SLED B treatment consisted of a batten $(23 \mathrm{~mm}$ wide) placed across the centre of the pot opening.

Attempts by a sea lion to enter a pot were deemed successful if a sea lion placed its head completely below the bottom of the neck structure and into the body of the pot. All other attempts were deemed unsuccessful. This measure of success was used as an indicator of the relative risk of drowning, but was not meant to represent a guarantee of an animal drowning. Sea lions that can place their head below the bottom of the neck will not be at risk of drowning, as they may not be able to get their maximum girth through the neck of the pot to become stuck. This conservative approach to the assessment of the risk of drowning in a pot was taken so as to ensure that the SLED design had a margin of error that took into account variability not

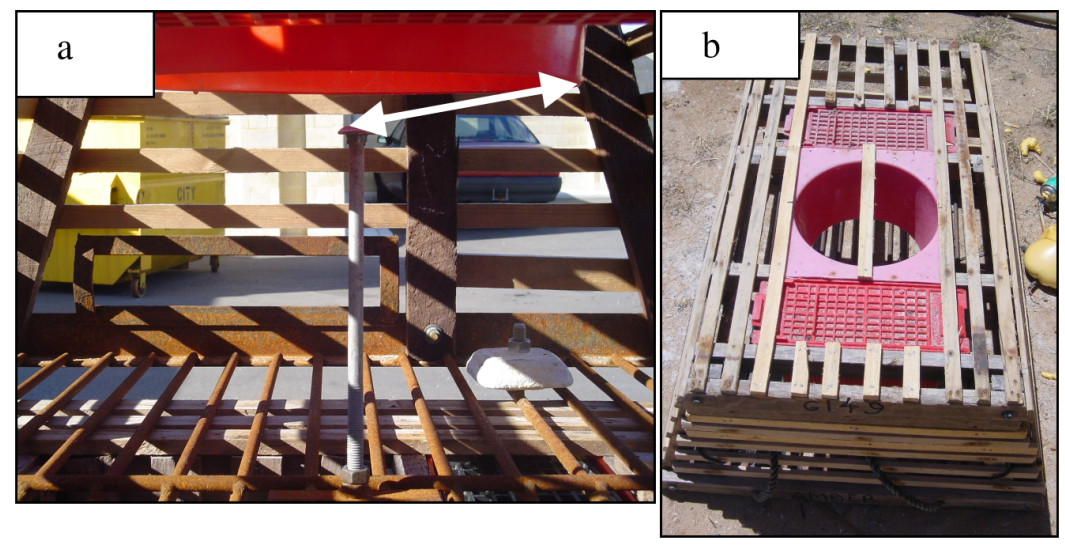

Fig. 3. The types of sea lion exclusion devices (SLEDs) trialled in lobster pots of the west coast rock lobster fishery. (a) SLED A, an upright steel rod attached to the base of the pot and extending up towards the neck (opening) of the pot. The arrow indicates the SLED-neck gap, with a maximum allowed distance of $132 \mathrm{~mm}$. (b) SLED B, a solid batten secured across the neck of the pot, which must result in a maximum $132 \mathrm{~mm}$ SLED-neck gap 
encountered in the experiment. This included exclusion of entry of sea lions smaller than those observed during the experiments and the possibility that the SLED might move in the pot during the rigours of commercial fishing.

Impact of SLEDs on catch rate and volume: The effect of different types of SLED design on catch rate was investigated using fishery-dependent trials on the mid-west coast. Each participating fisher $(n=15)$ had 10 pots modified with one of the SLED types, under supervision of DOF staff to ensure the devices were fitted in accordance with the recommendations. Fishers were asked to participate for as long as they remained in the proposed SLED zone. The SLED pots were distributed randomly throughout the fisher's gear, and the pot immediately following the SLED pot was defined as the control pot. This was to minimise the effect of catch variability between pots set on different habitats and substrates, which can be substantial (N. Caputi pers. comm.). Catch rates of legal and sub-legal size lobsters were recorded by the commercial operators on a daily basis for the SLED and control pots, and the mean daily catch rate per 10 pots was compared between treatments using a 2-tailed Student's $t$-test. DOF research staff collected these data on board each participating vessel for at least 2 fishing days to validate catch records and ensure that SLEDs had remained in the recommended position within the pot. A sub-sample of lobsters caught in the SLED and control pots were measured and mean size compared between the 2 treatments to determine whether there was any size selectivity in the 2 designs.

Commercial fishers were involved in the trial as volunteers and participated for varying lengths of time depending upon their willingness to record data, perceived impact of SLEDs on catch rate and their time spent fishing in the relevant area. As such, not all fishers participated for the same period of time.

ASL foraging behaviour. Animal handling and instrument deployment: Foraging behaviour was assessed using platform telemetry transmitters (PTTs, Sirtrack and Spot 5 tags, Wildlife Computers) and time-depth recorders (TDR, Mk9-Wildlife Computers). Animals were captured using specialised hoopnets (Fuhrman Diversified), physically restrained and anaesthetised using a mobile field gas (isofluorane-based) anaesthesia unit (Advanced Anaesthesia Specialists) (Gales \& Mattlin 1998). The recording instruments were initially glued to a section of neoprene and then attached to the animal's dorsal pelage using a quick-setting marine epoxy glue (Araldite $2017^{\circledR}$ ). A VHF radio transmitter tag was also attached to enable relocation of the animal to aid the recapture process. Mass, length and girth measurements were taken and the sex of the animal determined whilst the animal was anaesthetised.
Four separate deployments were performed: (1) 4 juveniles at Beagle Island on 27 and 28 March 2006; (2) 6 juveniles in Jurien Bay Marine Park from 19 to 21 May 2006; (3) 3 adult female-pup pairs at Beagle Island on 16 and 17 August 2006; and (4) 2 pups in the proposed SLED area in November 2006. All animals in the first 3 deployments were fitted with a PTT device, TDR and VHF unit, except for the pups, which were only fitted with a TDR and a VHF due to concerns about the mass and size of instruments. The 2 pups ( 10 to 14 mo of age) taken in November were both fitted with a PTT and VHF transmitter. Deployments were for a minimum of $2 \mathrm{wk}$ to ensure normal foraging behaviour resumed. Animals were recaptured (and anaesthetised when necessary) to enable the removal of the tags. All animal handling and experimental procedures were performed in accordance with the conditions provided by scientific permit SF 005288 and ethics permit DEC AEC 05/2008.

Spatial foraging data: The location data were accessed via the web-based Argos monitoring system (www.argos-system.org/). All obviously erroneous locations (i.e. inland and open ocean) and locations with low accuracy (class of hit $Z_{\text {; }}$ Argos classification see next paragraph) were removed. Velocity was calculated for travel between all pairs of successive PTTderived locations. The data were then filtered, removing locations that resulted in speeds of $>10 \mathrm{~km} \mathrm{~h}^{-1}$ for $5 \mathrm{~min}$, or $100 \mathrm{~km} \mathrm{~h}^{-1}$ for $1 \mathrm{~min}$ or $>500 \mathrm{~km} \mathrm{~h}^{-1}$ for any duration. Filtered locations for all individuals tagged were plotted on ArcGIS (ESRI 2004) to show the spatial characteristics of foraging in relation to tagging location, bathymetry and the proposed SLED area.

Locations provided by the Argos satellite system are graded according to their accuracy in order $3,2,1,0, \mathrm{~A}$, $B, \ldots, Z$ from highest to lowest. Filtered datasets were analysed to determine the proportion of each class hit from all data combined. It should be noted that the maximum accuracy of PTT-derived locations using the Argos system is $\pm 350 \mathrm{~m}$. Many locations at sea provided by the process above will derive positions with $>1 \mathrm{~km}$ error; as such the data should not be interpreted as a representation of the fine-scale foraging locations.

Dive data: TDRs were programmed to record depth every 2 s. These data were analysed using the programme Instrument Helper (Wildlife Computers). Dive analysis for all animals was performed on all dives equal to or greater than $4 \mathrm{~m}$ depth. Dive characteristics calculated for each animal included mean and maximum depth, dive duration, bottom time, foraging trip length and foraging efficiency (FE). FE was determined by dividing the total time at sea by the total bottom time (bottom time and post-dive surface interval, Ydenberg \& Clark 1989). Time spent diving, proportion of dive time spent on the sea bottom and FE were 
regressed against the mass of the animal. Frequency histograms of dive depth were produced for pup, juvenile and adult female cohorts combined to determine the depth profile of foraging habitats in relation to the proposed SLED zone (0 to $20 \mathrm{~m}$ ). Differences in the distribution of dive depths between cohorts were tested for using a Kolmogorov-Smirnov test.

\section{RESULTS}

\section{Characteristics of interaction and risk assessment}

\section{Rates of incidental capture}

The level of incidental bycatch of ASL has been relatively low, with only 34 incidental mortalities recorded over the last 2 decades (Fig. 2). There were also 6 reports of sea lions being released alive after capture. The annual survey provided the highest point estimate of incidental capture of 12 in 1999/2000, which was well above the highest total reported number of 6 incidental captures for any season (Table 1). Estimates from the phone survey were the lowest with an average of 1 incidental capture per season. The number of pot lifts per bycatch event for each season is expressed based on the maximum value provided by the four estimates of incidental capture. This resulted in an average value of 195337 pot lifts for every estimated incidental capture of an ASL over the course of the 5 fishing seasons between 1999/2000 and 2003/2004 (Table 1).

\section{Spatial and temporal patterns of interaction}

The reported interactions are concentrated around the central mid-west coast breeding colonies and haulout areas (Fig. 2). There were no recorded captures for the Houtman Abrolhos Islands or the greater
Perth area, which are, respectively, breeding and haulout areas for ASL (Gales et al. 1992). The majority of recorded mortalities $(80 \%)$ occurred in 0 to $10 \mathrm{~m}$ and all captures were confined to waters less than $20 \mathrm{~m}$. Locations of captures were all within $30 \mathrm{~km}$ of a known breeding location on the mid-west coast. There were no reports of captures of sea lions around the breeding colony of North Fisherman Island. However, anecdotal information provided to the authors suggests that captures of sea lions has occurred in this area.

Minimum age estimates of the individuals captured showed that animals were vulnerable to capture from an early age (5 to $6 \mathrm{mo}$ ) to over 18 mo of age (Fig. 4). The maximum estimated age at capture was $620 \pm$ $75 \mathrm{~d}$ (approximately $22 \pm 2.5 \mathrm{mo}$ ). The limited biological data provided by the fishermen who reported captures of ASL indicate that the sea lions caught were small (0.61 to $0.91 \mathrm{~m}$ long, data not shown), suggesting that pups were the predominant age class being caught. However, the distribution of estimated ages of captured animals shows that animals appear to be

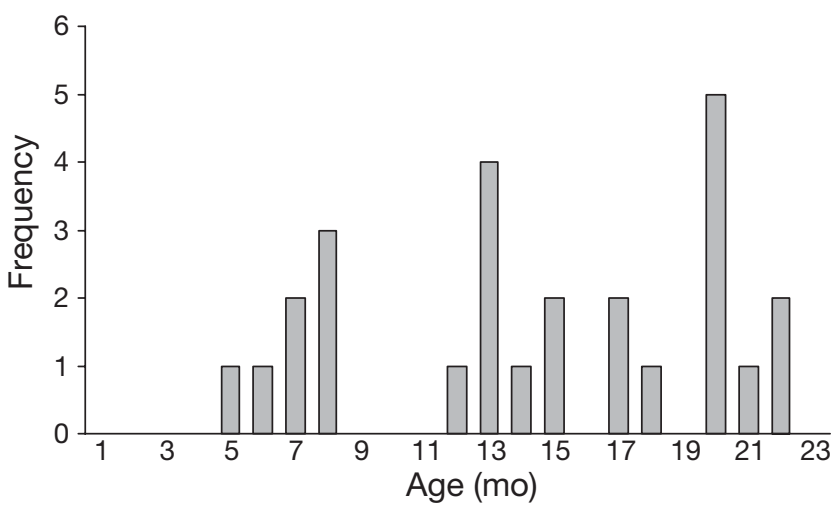

Fig. 4. Neophoca cinerea. Age at capture of sea lions in lobster pots. These estimates are based on the date of capture where provided $(\mathrm{n}=26)$ and the median date of the most recent breeding event of the nearest breeding colony. Fourteen reports of captures had insufficient information to calculate an age estimate

Table 1. Neophoca cinerea. Estimates of incidental captures of Australian sea lions (ASLs) in the west coast rock lobster fishery (WCRLF) for the past 5 fishing seasons using 4 methods. Estimates are rounded to whole numbers. Number of potlifts is the fishing effort in 0-20 m reported by the fishery from the area of interaction between ASLs and the WCRLF. CV: coefficient of variation; N/A: not available

\begin{tabular}{|c|c|c|c|c|c|c|}
\hline \multirow[t]{2}{*}{ Method } & \multicolumn{5}{|c|}{ Estimate of capture rate for period } & \multirow[b]{2}{*}{ Mean $(\mathrm{CV})$} \\
\hline & $1999 / 2000$ & $2000 / 2001$ & $2001 / 2002$ & $2002 / 2003$ & $2003 / 2004$ & \\
\hline Annual survey & 12 & 8 & 4 & 0 & 3 & $5.4(0.86)$ \\
\hline Volunteer logbook & N/A & 0 & 6 & 4 & 3 & $3.25(0.72)$ \\
\hline Total no. reported interactions & 6 & 5 & 2 & 2 & 4 & $3.8(0.47)$ \\
\hline Phone survey & 1 & 1 & 1 & 1 & 1 & $1(0)$ \\
\hline No. potlifts in $0-20 \mathrm{~m}\left(10^{3}\right)$ & 1162 & 1143 & 1495 & 1212 & 1089 & $1253(0.13)$ \\
\hline No. potlifts per capture & 96874 & 142942 & 299106 & 242427 & 272426 & $195337(0.47)$ \\
\hline
\end{tabular}


vulnerable to capture up until and after weaning (approx. 18 mo old, Higgins \& Gass 1993; 18 to 22 mo, Fig. 4).

The relationship between the timing of the ASL breeding season relative to the WCRLF season did not appear to explain the variation in capture rate between fishing seasons. The maximum reported number of 6 captures in the 1999/2000 fishing season coincided with the end of a breeding cycle. However, this pattern was repeated 2 breeding seasons later in the 2002/ 2003 fishing season, when only 2 mortalities were reported (Fig. 5). Captures were recorded throughout the fishing season cycle, and were also recorded throughout the breeding cycle of the sea lion, including some captures during the breeding season. These

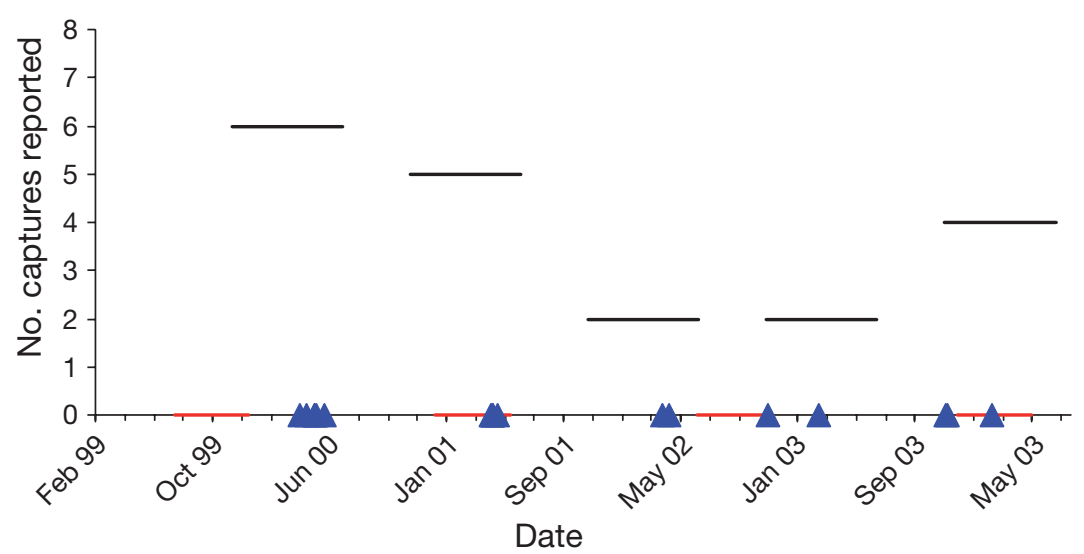

Fig. 5. Neophoca cinerea. Temporal relationships of fishing season (black line, Nov-June), sea lion breeding activity (red line, $x$-axis) and reported dates of incidental captures of sea lions ( $\boldsymbol{\Delta}$ ) from the 1999/2000 season to 2003/2004 $(\mathrm{n}=19)$. This period of time represents the most concise and concerted effort in bycatch data collection. The reported numbers of incidental captures of Australian sea lion per fishing season are shown on the $y$-axis and represented by the black line for the respective annual fishing season data may be affected by variable rates of reporting from the fishery among fishing seasons.

Average fishing effort (number of pot lifts) among fishing grids in 0 to $20 \mathrm{~m}$ varied considerably; however, it did not appear to explain the variation in bycatch rate among different areas $\left(r^{2}=0.0024\right)$. The $\chi^{2}$ analysis was highly significant $\left(\chi^{2}=49.7, \mathrm{df}=7, \mathrm{p}<0.001\right)$, indicating that mortalities were not distributed relative to fishing effort. The fishing transect adjacent to the town of Jurien Bay accounted for nearly half of all recorded mortalities ( $40 \%$ ), but only $12 \%$ of the average fishing effort (data not shown). This analysis may be biased by regional variation in the reporting of mortalities across the fishery and patterns of foraging behaviour of vulnerable-sized sea lions.

Of the 6 sea lions captured that were still alive upon retrieval of the pot, 4 were in close proximity $(<5 \mathrm{~km})$ to the breeding colonies of Buller and Beagle Island. Pup and juvenile ASLs have very short breath-hold capacity (3 to $5 \mathrm{~min}$, Campbell \& Holley 2006, Fowler et al. 2006) relative to the soak time of lobster pots, which is a minimum of $14 \mathrm{~h}$. The relatively high proportion of alive to dead animals based on the time that pots are available to sea lions suggests that some animals may be attracted to pots just prior to or during hauling.

\section{Population viability analysis}

The harvesting of juvenile sea lions at a rate comparable to the reported

Table 2. Outcomes of the population viability analysis (PVA) assessing the impact of hypothetical rates of incidental mortality. Simulations over 100 breeding cycles produced an estimate of exponential rate of population growth (r) and conservation status of each colony based on probability of extinction for 2 population scenarios, stable and exponentially increasing at approximately $2 \%$ per breeding season. Hypothetical harvest rates per breeding cycle are converted to the number of incidental mortalities per fishing season. V: vulnerable; End: endangered

\begin{tabular}{|c|c|c|c|c|c|c|}
\hline \multirow[t]{2}{*}{ Colony } & \multirow{2}{*}{$\begin{array}{l}\text { Harvest rate/ } \\
\text { breeding cycle }\end{array}$} & \multirow{2}{*}{$\begin{array}{l}\text { Mortalities per } \\
\text { fishing season }\end{array}$} & \multicolumn{2}{|c|}{ Stable population } & \multicolumn{2}{|c|}{ Increasing population } \\
\hline & & & $\mathrm{r}$ & Status & $\mathrm{r}$ & Status \\
\hline \multirow[t]{4}{*}{ Beagle } & 1 & 4 & -0.001 & V & 0.015 & $\mathrm{~V}$ \\
\hline & 2 & 8 & -0.030 & $\mathrm{~V}$ & 0.008 & $\mathrm{~V}$ \\
\hline & 3 & 12 & -0.048 & End & 0.004 & End \\
\hline & 4 & 16 & -0.060 & Extinct & -0.007 & End \\
\hline \multirow[t]{4}{*}{ North Fisherman } & 1 & 4 & -0.018 & V & 0.013 & $\mathrm{~V}$ \\
\hline & 2 & 8 & -0.040 & End & -0.020 & End \\
\hline & 3 & 12 & -0.055 & Extinct & -0.006 & End \\
\hline & 4 & 16 & -0.068 & Extinct & -0.022 & End \\
\hline \multirow[t]{4}{*}{ Buller } & 1 & 4 & -0.020 & End & 0.008 & $\mathrm{~V}$ \\
\hline & 2 & 8 & -0.043 & End & -0.013 & End \\
\hline & 3 & 12 & -0.062 & Extinct & -0.020 & Extinct \\
\hline & 4 & 16 & -0.079 & Extinct & -0.042 & Extinct \\
\hline
\end{tabular}


incidental mortality rate in the WCRLF resulted in declines of population abundance and an increased risk of extinction (Table 2). The conservation status of the 3 management units was upgraded to a higher risk category in the majority of cases of harvest simulation in this study (Table 2). It is apparent that chronic levels of low incidental mortality across the fishery could result in the extinction of Buller, North Fisherman and Beagle Islands within $100 \mathrm{yr}$ for both the stable and increasing population trajectories. The classification of status of these colonies as endangered, critically endangered or extinct, based on Mace \& Lande (1991), shows that the elimination or reduction of incidental mortality from the WCRLF is an important component in the long term viability of these 3 breeding colonies. The level of reported incidental mortality would undoubtedly affect the growth/recovery of these colonies.

\section{SLED evaluation}

Device efficacy and behavioural interaction between sea lions and pots

It was apparent that the setting of SLED A affected the rate at which vulnerable-sized sea lions could gain entry to the pot (Table 3$)$. The flush $(0 \mathrm{~mm})$ and $20 \mathrm{~mm}$ settings of the SLED both seemed to virtually eliminate entry of sea lions into the pots, but there was a gradual decline in efficacy of the device, to around $50 \%$ exclusion rate, at the $60 \mathrm{~mm}$ setting. The control setting appeared to exclude around 1 in every 5 attempts, but this reflects the background variation in behaviour of ASL around lobster pots, rather than its efficacy at physically excluding the sea lion. SLED B was effective in eliminating the entry of all vulnerable-sized sea lions (data not shown). Given that both the flush and $20 \mathrm{~mm}$ settings of SLED A were effec-

Table 3. Effectiveness of various settings of sea lion exclusion device (SLED) type A in preventing entry of Australian sea lions (ASL) into a redneck lobster pot. The control setting was a normal pot without a SLED. The setting (in $\mathrm{mm}$ ) is the distance that the top of the SLED sits below the horizontal plane of the bottom of the neck structure (see Fig. 3a). Values in parentheses show number of attempted entries

\begin{tabular}{|lr|}
\hline SLED setting & $\%$ exclusion of ASL from pot \\
\hline CONTROL & $18(113)$ \\
$0 \mathrm{~mm}$ (flush) & $100(50)$ \\
$20 \mathrm{~mm}$ & $95(77)$ \\
$40 \mathrm{~mm}$ & $72(63)$ \\
$60 \mathrm{~mm}$ & $55(32)$ \\
\hline
\end{tabular}

tive, the $20 \mathrm{~mm}$ setting of SLED A was recommended for commercial catch trials. This was the equivalent to a maximum SLED-neck gap of $132 \mathrm{~mm}$. This setting was preferred to the higher one (flush) as it was thought that the lower the height of the SLED, the lower the impact on target-species catch rate. SLED B was also recommended for commercial catch rate trials, as it excluded the entry of all sea lions and complied with the SLED-neck gap setting of $132 \mathrm{~mm}$. These devices were trialed in the commercial fishery to determine the impact on catch rate and size of lobsters caught.

Examples of interactions between sea lions and lobster pots with and without SLEDs can be seen in the associated images in the Supplementary Material (available at: www.int-res.com/articles/suppl/ n005p345_app.pdf

Impact of SLEDs on catch rate and volume

SLED A $(20 \mathrm{~mm})$ showed no discernible impact on catch rate for fishing effort in 0 to $20 \mathrm{~m}$ within the proposed mandatory SLED zone. Comparison of the daily catch in the 10 experimental SLED (14.5 \pm 1.5 , $\mathrm{n}=165)$ and normal pots $(15 \pm 1.8, \mathrm{n}=165)$ showed no significant difference in the number of legal-sized lobsters caught. There was a similar pattern for sublegal-sized lobsters (data not shown, for information on the legal size of lobsters go to www.fish.wa. gov.au/docs/pub/FishingRockLobsters/FishingforRock Lobster2008-Dec.pdf). Approximately 1650 pot lifts were conducted in this trial for each treatment. A subset of approximately 300 lobsters from each treatment were measured, and no difference in mean carapace size was evident between the pots fitted with SLED A $(79.5 \pm 7.5 \mathrm{~mm})$ and normal pots $(79.8 \pm$ $7.0 \mathrm{~mm})$.

Daily catch rates in shallow waters (0 to $20 \mathrm{~m}$ ) in pots fitted with SLED B showed a $14 \%$ reduction in catch rate of legal-sized lobsters compared to the control pots, though this was marginally non-significant $(t=$ $1.85, \mathrm{df}=52, \mathrm{p}=0.06$ ). There was no discernible difference in the mean size of lobsters caught in these 2 pots with very similar distributions, as seen in the SLED A trials above.

Some of the participating fishers continued using the SLEDs in deeper water outside of the proposed zone and recording catch data. Significant differences were seen in the mean catch rate of the 10 experimental and normal pots for both the SLED A $(t=4.7, \mathrm{df}=144, \mathrm{p}<$ $0.001)$ and SLED B $(t=2.6, \mathrm{df}=73, \mathrm{p}=0.01)$ treatments in water $>20 \mathrm{~m}$ deep. In both cases the SLED pots caught significantly fewer legal-sized lobsters than the normal pots. 


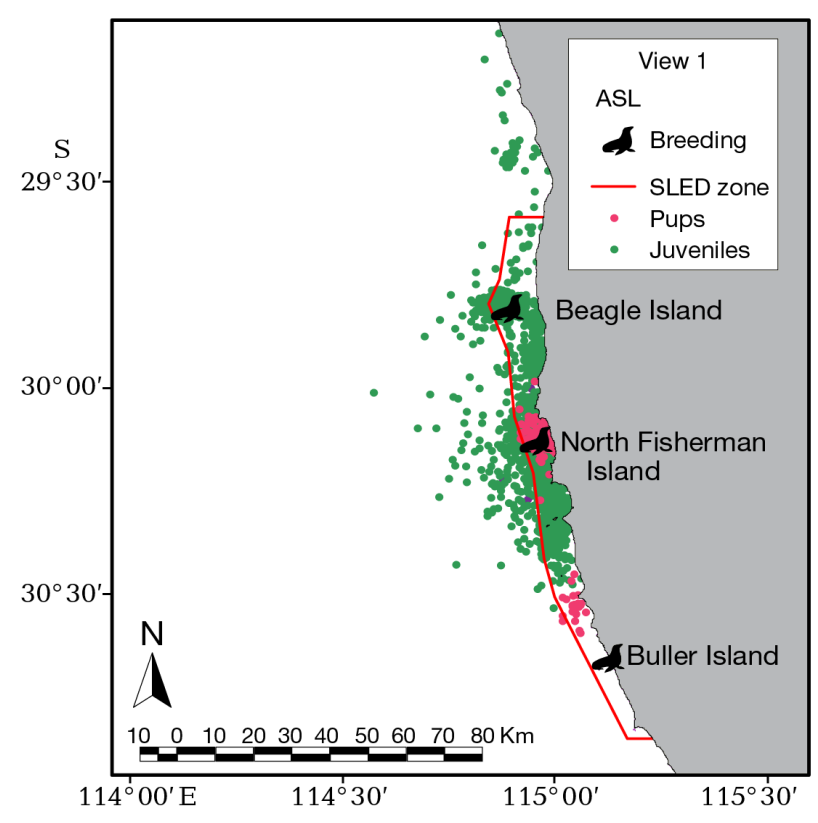

Fig. 6. Neophoca cinerea. At-sea locations provided by platforms transmitter terminals for pups $(\mathrm{n}=2)$ and juveniles $(\mathrm{n}=$ 10) sampled within the proposed sea lion exclusion device (SLED) zone. All locations for pups and a majority of the juvenile locations were within the boundaries of the proposed SLED zone. ASL: Australian sea lion

\section{ASL foraging behaviour}

\section{Spatial foraging data}

At-sea locations were grouped for each of the pup and juvenile cohorts from the various deployments to represent the foraging areas of the most vulnerable age classes along the central west coast (Fig. 6). The percentage of each location class provided by the filtered dataset of the satellite locations of all animals combined in this study was as follows: $3: 18 \% ; 2: 18 \%$; 1: $23 \%$; 0: $11 \%$; A: $13 \%$; and B: $17 \%$. This provides a relatively high proportion of hits with expected accuracy of less than $1 \mathrm{~km}(3,2,1,0)$.

The majority of locations were within the proposed SLED zone, with some excursions beyond the limits. Some of these locations, especially those to seaward of the SLED zone may be erroneous based on the accuracy of the Argos-derived locations. However, there was 1 excursion beyond the northern limit of the zone that extended for nearly $100 \mathrm{~km}$.

Two commercial rock lobster fishers observed one of the tagged juveniles in the vicinity of their fishing gear over several days within the confines of the proposed SLED zone. The animal was observed around the area $\left(29.85^{\circ} \mathrm{S}, 114.96^{\circ} \mathrm{E}\right)$, in close proximity to the fishermen's line of lobster pots. On one occasion the animal was observed to be eating lobster whilst on the surface.
Dive data

TDR tags were deployed on 16 individuals and 10 tags were retrieved with recoverable data. Tags were deployed for $25 \pm 2$ d (mean $\pm \mathrm{SE}$ ). Only 2 pups provided information on diving behaviour and they showed quite different diving rates, between 18 and 46 dives $h^{-1}$. Juveniles $(n=6)$ dived at a mean rate of 25.2 \pm 1.7 dives $h^{-1}$ and the 2 adult females recaptured dived at a rate of $19.0 \pm 2.1$ dives $\mathrm{h}^{-1}$. Mean dive depth and maximum dive depth increased with size (mass), but the relationships were not significant based on these limited data (mean depth: $\mathrm{r}^{2}=0.40, \mathrm{p}=0.051$; max depth: $\left.\mathrm{r}^{2}=0.26, \mathrm{p}=0.13\right)$.

The proportions of time at sea spent diving, on the benthos (FE) and the proportion of the diving time spent on the benthos (bottom time:dive time) increased significantly with size (Fig. 7; diving: $\mathrm{r}^{2}=0.53, \mathrm{p}<0.01$; FE: $r^{2}=0.60, p<0.01$, bottom time:dive time: $r^{2}=0.57$, $\mathrm{p}<0.01$ ). Interestingly, the relationship between the first 2 variables and mass showed a similar-shaped curve, but the relationship of mass and bottom time:dive time was much flatter than for the other 2 variables. This suggests that dive shapes are similar among cohorts but that the proportion of time at sea spent diving increases more rapidly during development. Mean dive length and mean foraging trip length increased significantly with size $\left(\mathrm{r}^{2}=0.60, \mathrm{p}<0.01, \mathrm{r}^{2}=\right.$ 0.77, p $<0.01$, respectively).

Cumulative frequency histograms for each cohort (Fig. $8 \mathrm{a}-\mathrm{c}$ ) were created to determine the proportion of

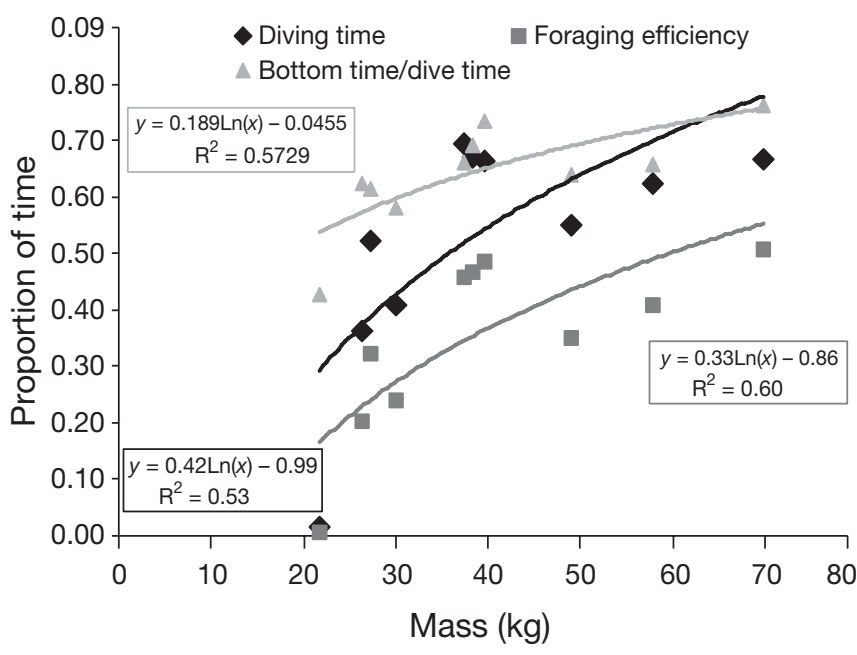

Fig. 7. Neophoca cinerea. Regression of 3 variables of diving performance on mass for 10 sea lions ( 1 pup, 7 juveniles and 2 cows) for which temperature and depth recorder data were retrieved. There was a positive relationship for all 3 variables with relatively small juveniles ( 35 to $40 \mathrm{~kg}$ ) achieving comparable levels of dive performance to those of adult females 


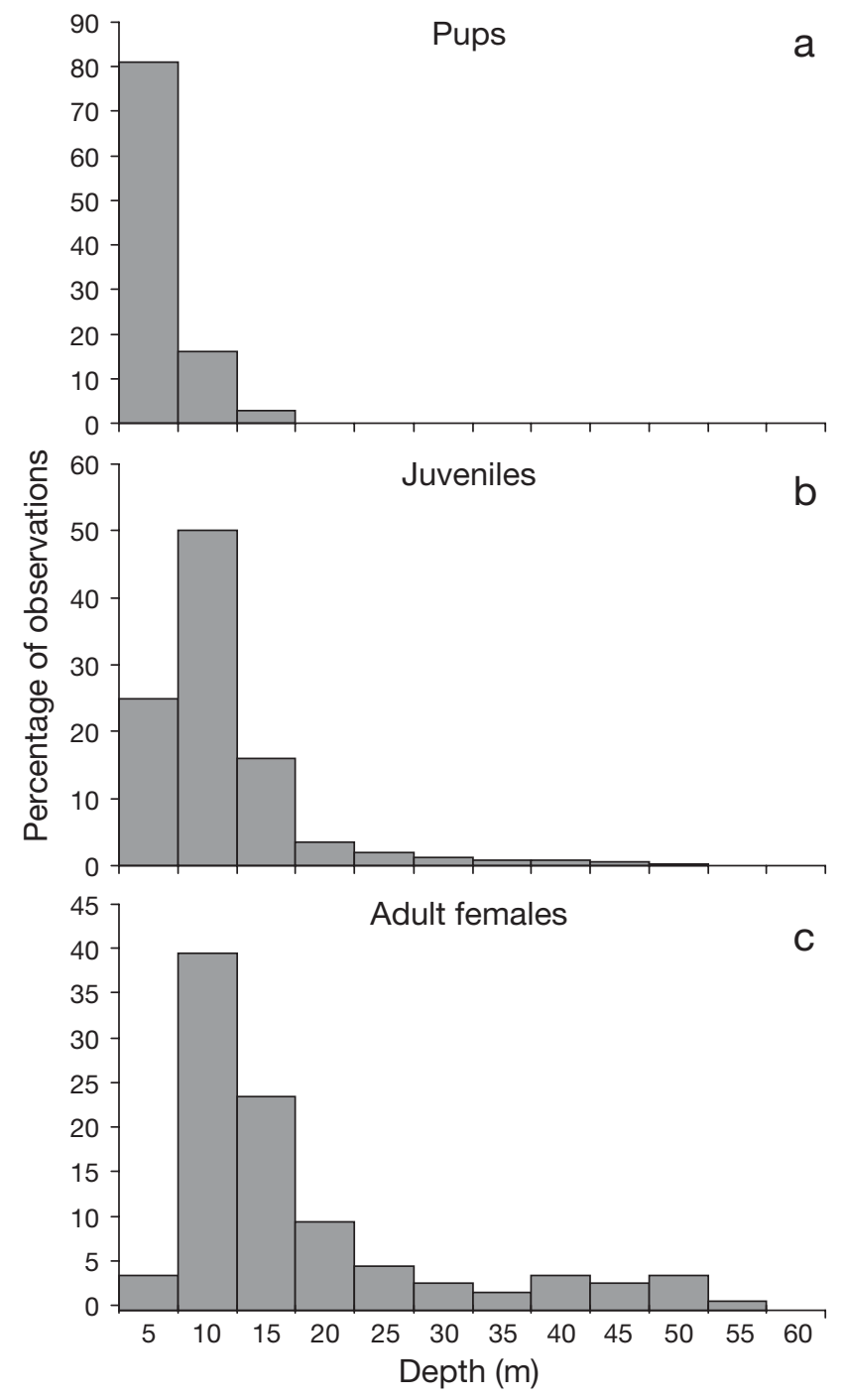

Fig. 8. Neophoca cinerea. Sea lion dive depths for the 3 cohorts tagged. The dive depths were binned in $5 \mathrm{~m}$ ranges, with the maximum depth of the bin shown on the $x$-axis. (a) All depths recorded by 6 to 10 mo old pups were $<20$ m, with greater than $90 \%$ of recorded dives $<10 \mathrm{~m}$. (b) More than $90 \%$ of recorded juvenile diving activity occurred at depths $<20 \mathrm{~m}$. Note the long tail of the distribution, showing the development of deeper diving to a maximum of $50 \mathrm{~m}$ in larger juveniles. (c) Nearly $80 \%$ of recorded diving activity in adult females was in depths $<20 \mathrm{~m}$. This distribution has a secondary peak of diving activity 35-50 m Distribution of dive depths between all pairwise cohort comparisons was significantly different (Kolmogorov-Smirnov test, $\mathrm{p}<0.001$ )

diving activity to depths less than $20 \mathrm{~m}$, equivalent to the mandatory SLED zone. The proportion of dives less than $20 \mathrm{~m}$ was $100 \%$ for pups, over $90 \%$ for juveniles and nearly $80 \%$ for adult females. Distribution of all dives by depth for each cohort showed the slow development of diving in this population (Fig. 8a-c). The majority of diving occurred in water $<20 \mathrm{~m}$ deep for all cohorts. Adult females exhibited a greater extent of diving effort in waters $>20 \mathrm{~m}$, and a secondary peak of diving activity was evident particularly in depths of 35 to $50 \mathrm{~m}$.

\section{DISCUSSION}

\section{Incidental capture}

This paper reports a low level of capture of ASLs in the WRLF, with 34 incidental mortalities recorded over approximately $20 \mathrm{yr}$. In addition there were 6 reports of animals being released alive after having been captured. The largest number of incidental captures reported in a single fishing season was 6 in both 1999 and 2000, similar to estimated numbers for this species published in a review of incidental mortality of Australian pinnipeds (Shaughnessy et al. 2003).

Extrapolation of the reported levels of capture to estimate an annual bycatch rate across the whole fishery produced a range of values from 0 to $12 \mathrm{ind}$. Three of the methods used to calculate a seasonal bycatch rate suggested that the minimum number of incidental captures was 4 to 5 per season. Due to the spatially discrete patterns of bycatch events, low frequency of these events and the fishery-dependent nature of these data, there is some uncertainty around the estimates produced by these methods. The rate of bycatch events, or number of pot lifts per mortality, provides a minimum estimate of the level of mortality of ASL in other pot-based fisheries.

Sea lions were captured up to $28 \mathrm{~km}$ from the nearest breeding colony. This suggests that pup/juvenile Australian sea lions on the west coast of Western Australia are capable of dispersing at least this distance from their natal site. All captures were recorded in waters $<20 \mathrm{~m}$ deep, with the majority occurring in water $<10 \mathrm{~m}$ deep. Estimates of the minimum age of captured animals in this study showed that they are potentially vulnerable to capture from the age they first develop benthic diving behaviours (approximately $6 \mathrm{mo}$, Fowler et al. 2006) up until at least $18 \mathrm{mo}$, a minimum of $12 \mathrm{mo}$ of their life and possibly longer. It is difficult to distinguish animals older than this from the younger cohort without more biological information from the captured animal. This suggests that the period of vulnerability to capture in the pots of the WCRLF will overlap with every fishing season and that some ASLs may be vulnerable to capture for more than 1 fishing season. Any appropriate management response would need to operate throughout every fishing season, as there would always be the potential of incidental capture.

The report of 6 animals being alive upon retrieval of the pot is an intriguing facet of these data. Based on a conservative estimate of the soak time of the pot (18 h) and the relative breath-hold capacity of a young sea 
lion ( $3 \mathrm{~min}$ ), the ratio of alive to dead captures would be close to 1:360. The reported ratio of approximately 1:7 alive to dead captures suggests that sea lions may target pots just prior to or during retrieval. There does not appear to be any obvious explanation for this behaviour, as animals would be unaware as to which pot would be pulled next, and getting into a pot that is already being retrieved would be difficult. An alternative explanation is that the level of reporting of sea lions alive after capture was much higher than the reporting of dead sea lions, due to concerns of fishers over the consequences of bycatch of threatened species. We may infer from these data that the rate of incidental mortality of ASLs in the rock lobster fishery may be much higher than these data indicate.

\section{PVA analysis}

Whilst the reported level of capture is low, especially in comparison to other reported interactions (e.g. New Zealand sea lions in Wilkinson et al. 2003, Chilvers 2008, this Theme Section), the rate is sufficient to adversely impact the viability of the west coast breeding colonies. The PVA shows that for both trajectories of population growth the maximum estimated level of incidental mortality per fishing season reported in this paper $(n=12)$ would result in the 3 colonies either being classified as endangered or likely to go extinct within 100 breeding cycles. Even the low estimates ( $\mathrm{n}=4$ to 8 ) of chronic incidental mortality would result in population decline and a move to a higher risk category for Buller Island and North Fisherman Island colonies. The likelihood that the real rate of incidental mortality is even higher than that estimated in the present study means that the risk posed to the viability of the 3 colonies of ASL on the central west coast is even greater than that demonstrated by the PVA.

The susceptibility of ASL populations to chronic, low levels of incidental mortality indicated by this study is in keeping with the findings of Goldsworthy \& Page (2007) for populations of ASLs in South Australia. The crucial factor for these populations is the exclusive natal site philopatry of the female sea lions, resulting in isolated female breeding populations (Campbell et al. 2008). These findings may also be an underestimate of the rate of decline, as there is no inclusion of an Allee effect (Allee et al. 1949), which will accelerate population decline. Other potential genetic effects which may increase the rate of population decline and extinction probability in small populations were not included in the model (Soulé 1986, Whitlock \& McCauley 1990, Amos \& Balmford 2001), further contributing to a potential underestimate of risk.
This PVA supported the recommendation of the SLSRG that the reported levels of incidental mortality may be affecting the viability and/or recovery of these colonies and that the elimination or reduction of this level of incidental mortality was the appropriate management action.

\section{SLEDs}

The experimental trials showed that it is possible to virtually eliminate the entry of vulnerable-sized sea lions into the lobster pots used in the WCRLF with both types of SLED. Two settings of SLED A flush and $20 \mathrm{~mm}$ ) resulted in virtual elimination of entry of vulnerable-sized sea lions. An increase in the SLED-neck gap for SLED A resulted in an increased rate of entry for vulnerable-sized sea lions. The SLED B configuration resulted in complete elimination of entry of all pup/juvenile animals. The creation of the SLED-neck gap measurement allowed the use of SLED A in the many configurations of pot types used in the fishery (see supplementary material). The configuration of SLED B was designed to result in the same maximum SLED-neck distance as that for SLED A (132 mm). As the legislation allows for a vast array of pot structures and neck sizes it was important to be able to determine how SLED A could be adapted to all types of pots in both the commercial and recreational fisheries. These results supported the recommendations of the SLSRG for the design of a pot modification that was cheap, easy to install and could be used on all existing pot types in the industry.

The results from the commercial catch rate trials suggested that the impact of the proposed SLEDs on catch rate and catch volume in the proposed mandatory SLED zone would be minimal if not non-existent. No significant difference in the catch rates and mean size of lobsters was detected for pots fitted with either SLED in the waters of the proposed SLED zone ( 0 to $20 \mathrm{~m})$, though there was a $14 \%$ reduction in the mean catch rate for the pots fitted with SLED B.

\section{Foraging behaviour of ASLs in relation to the proposed SLED zone}

The combination of the at-sea locations and the diving data provided by the tagging research suggests that pup and juvenile sea lions forage predominantly within the confines of the proposed SLED zone. Whilst the range and depths recorded by some of the larger juvenile animals extended beyond the SLED zone, some of these animals were approaching or were probably beyond the age/size at which they were vulnera- 
ble to capture in lobster pots. Whilst the proposed SLED zone may not cover $100 \%$ of the potential foraging range of all vulnerable animals, our data suggest that nearly $95 \%$ of all foraging activity of vulnerablesized sea lions from the 3 breeding colonies affected would fall within the proposed SLED zone, assuming that foraging behaviour of ASLs from Buller Island is similar to that from other colonies in the area.

The extensive use of the shallow water habitats by all age classes studied (pups, juveniles, adult females) differs from that seen at another ASL colony, Kangaroo Island, where mean dive depths were 2 to 3 times greater (Fowler et al. 2006). This specialisation in westcoast ASLs may be due to different bathymetry, increased prey abundance in shallow water habitats, prey specificity and/or predator avoidance. It is believed that ASLs in this area prey preferentially on Octopus tetricus and western rock lobster (Gales \& Cheal 1992, R. Campbell unpubl. data); however it is impossible to know what proportion of these items may be taken from lobster pots. Deployments occurred both during and outside of WCRLF fishing activity and there was no discernible difference in foraging locations; further tracking of juvenile ASLs has confirmed the consistency of foraging patterns independent of rock lobster fishing activity (R. Campbell unpubl. data).

\section{Implementation of SLED areas and future management}

The mandatory use of SLEDs in the defined zone (Fig. 2) was introduced for the 2006 and 2007 fishing season. Modification of the Fish Resources Management Act (1984) defined the approved SLED designs to be used and the mandatory area for their use. Whilst the impetus for mitigating sea lion bycatch stemmed from the incidental mortality in the commercial fishery, the legislation applied to the recreational sector as well. Compliance rates of $95 \%$ or greater were recorded in both the commercial and recreational sectors in the first season of implementation (DOF 2007). No incidental captures were reported in either the commercial or recreational sector for this season.

Independent monitoring and verification of the incidental capture rate of sea lions in the WCRLF is logistically difficult, due to the low incidence of the events and the very high proportion of fishing effort that would have to be monitored. Verification in this instance is provided indirectly, by means of ensuring that the SLED remains an effective impediment to sea lion entry into pots and that compliance remains very high through the monitoring of commercial and recreational pots in the mandatory zone.
Moves by foraging vulnerable-sized sea lions into deeper waters outside of the mandatory zone may expose them to incidental capture. However, we believe sea lions do not forage to such a great extent from lobster pots. Furthermore, observations of sea lions able to remove lobsters from pots fitted with SLEDs through the escape gaps and battens suggests that there is little motivation for sea lions to change foraging patterns to exploit pots without SLEDs. It would be valuable to follow up on the foraging behaviour of pup and juvenile sea lions in the future to investigate whether changes in foraging behaviour have occurred. If human activity leads to depletion of prey resources in the shallow water ( 0 to $20 \mathrm{~m}$ ) habitats by human activity occurs, this may force pup and juvenile sea lions to forage deeper and further afield than at present, thus exposing them to the risk of capture in lobster pots.

Acknowledgements. Many thanks to all the fishermen of the rock lobster fishery who provided advice, reported bycatch events and helped with designing and trialing SLEDs. Constructive advice on the SLED design was also provided by the Western Rock Lobster Council, the peak fishing body, which proved of great assistance. The authors thank all those involved in the capturing, tagging and recapturing of animals in the west coast regions. In particular, the staff at the regional DEC office of Jurien Bay provided much needed seal wrangling support. Supervision of the project and improvement of earlier drafts was provided by N. Caputi, and the final paper was helped immeasurably by comments from 2 anonymous referees. All research activities were performed under the auspices of the scientific (SF 005288) and ethics permits (05/2008) provided by the Australian Department of Environment and Conservation.

\section{LITERATURE CITED}

Allee W, Emerson A, Park O, Park T, Schmidt K (1949) Principles of animal ecology. Saunders, Philadelphia

Amos W, Balmford A (2001) When does conservation genetics matter? Heredity 87:257-265

Anonymous (1996) Seal friendly lobster potting. Southern Fisheries 4:2

Boyd IL (1991) Environmental and physiological factors controlling the reproductive cycles of pinnipeds. Can J Zool 69:1135-1148

Campbell R (2005) Historical distribution and abundance of the Australian sea lion (Neophoca cinerea) on the west coast of Western Australia. Fisheries Research Report No.148, Department of Fisheries, Perth

Campbell RA, Holley DK (2006) Foraging ecology of Australian sea lions and their relationship with commercial fishing and marine protected areas. Report to the Department of Environment and Heritage, Canberra

Campbell RA, Gales NJ, Lento GM, Baker CS (2008) Islands in the sea: extreme female natal site fidelity in the Australian sea lion, Neophoca cinerea. Biol Lett 4:139-142

Chilvers BL (2008) New Zealand sea lions Phocarctos hookeri and squid trawl fisheries: bycatch problems and management options. Endang Species Res 5:193-204

Cobb JS (1981) Behaviour of the Western Australian spiny 
lobster, Panulirus cygnus George, in the field and laboratory. Aust J Mar Freshw Res 32: 399-409

DOF (Department of Fisheries) (2003) Report of the western rock lobster fishery / sea lion interaction scientific reference group. Department of Fisheries, Perth

DOF (Department of Fisheries) (2007) Report of the western rock lobster fishery / sea lion interaction scientific reference group. Department of Fisheries, Perth

ESRI (2004) ArcGIS v9. A spatial analysis computer programme. ESRI Press, Redlands, CA

Fowler SL, Costa DP, Arnould JPY, Gales NJ, Kuhn CE (2006) Ontogeny of diving behaviour in the Australian sea lion: trials of adolescence in a late bloomer. J Anim Ecol 75:358-367

Gales N, Cheal A (1992) Estimating diet composition of the Australian sea-lion (Neophoca cinerea) from scat analysis: an unreliable technique. Wildl Res 19:447-456

Gales NJ, Mattlin RH (1998) Fast, safe field-portable gas anaesthesia for otariids. Mar Mamm Sci 14:355-361

Gales NJ, Cheal AJ, Pobar GJ, Williamson P (1992) Breeding biology and movements of Australian sea lions, Neophoca cinerea, off the west coast of Western Australia. Wildl Res 19:405-416

Gales NJ, Shaughnessy PD, Dennis TE (1994) Distribution, abundance and breeding cycle of the Australian sea lion, Neophoca cinerea. J Zool 234:353-370

Goldsworthy SD, Page B (2007) A risk assessment approach to evaluating the significance of seal bycatch in two Australian fisheries. Biol Conserv 139:269-285

Goldsworthy SW, Bulman C, He X, Littnan C (2003). Trophic interactions between marine mammals and Australian fisheries: an ecosystem approach. In: Gales NJ, Hindell M, Kirkwood R (eds) Marine mammals: fisheries, tourism and management issues. CSIRO Publishing, Melbourne, p 62-99

Higgins LV (1993) The non-annual, nonseasonal breeding cycle of the Australian sea lion, Neophoca cinerea. J Mammal 74:270-274

Higgins LV, Gass L (1993) Birth to weaning: parturition, duration of lactation, and attendance cycles of Australian sea lions (Neophoca cinerea). Can J Zool 71:2047-2055

International Risk Consultants (2001) Western Rock Lobster Ecological Risk Assessment. Report to Department of Fisheries, Western Australia. International Risk Consultants, Perth

Lacy RC, Borbat M, Pollak JP (2006) Vortex: A stochastic simulation of the extinction process. V. 9.70. Chicago Zoological Society, Brookfield, IL

Ling JK (1999) Exploitation of fur seals and sea lions from

Editorial responsibility: David Hodgson,

University of Exeter, Cornwall Campus, UK
Australian, New Zealand and adjacent subantarctic islands during the eighteenth, nineteenth and twentieth centuries. Aust Zool 31:323-350

Ling JK, Walker GE (1978) An 18 month breeding cycle in the Australian sea lion? Search 9:464-465

Mace GM, Lande R (1991) Assessing extinction threats: towards a re-evaluation of IUCN threatened species categories. Conserv Biol 5:148-157

Mawson PR, Coughran DK (1999) Records of sick, injured and dead pinnipeds in Western Australia 1980-1996. J R Soc West Aust 82:121-128

McKenzie J, Goldsworthy SD, Shaughnessy PD, McIntosh R (2005) Understanding the impediments to the growth of Australian sea lion populations. Report to the Dept. of Environment and Heritage. Prepared by the South Australian Research Development Institute, Adelaide

Moritz C (1994) Defining 'evolutionary significant units' for conservation. Trends Ecol Evol 9:373-375

Reijnders PJH, Brasseur S, Toorn J, Wolf P, Boyd I, Harwood J, Lavigne D, Lowry L (1993) Seals, fur seals, sea lions and walrus: Status survey and conservation action plan. IUCN, Gland

Shaughnessy PD (1999) The action plan for Australian seals. Environment Australia, Canberra

Shaughnessy PD, Kirkwood R, Cawthorn M, Kemper C, Pemberton D (2003). Pinnipeds, cetaceans, and fisheries in Australia: a review of operational procedures. In: Gales NJ, Hindell M, Kirkwood R (eds) Marine mammals: Fisheries, tourism and management issues. CSIRO Publishing, Melbourne, p 136-152

Soulé M (1986) Conservation biology: the science of scarcity and diversity. Sinauer Associates, Sunderland, MA

Whitlock MC, McCauley DE (1990) Some population genetic consequences of colony formation and extinction: genetic correlations within founding groups. Evolution 44: $1712-1724$

Wilkinson I, Burgess J, Cawthorn M (2003). New Zealand sea lion and squid: managing fisheries impacts on a threatened mammal. In: Gales NJ, Hindell MA, Kirkwood R (eds) Marine mammals: fisheries, tourism, and management issues. CSIRO Publishing, Melbourne, p 192-207

Woodley TH, Lavigne DM (1993) Potential effects of incidental mortalities on the Hooker's sea lion (Phocarctos hookeri) population. Aquat Conserv: Mar Freshw Ecosyst 3:138-148

Ydenberg RC, Clark CW (1989) Aerobiosis and anaerobiosis during diving of Western grebes: an optimal foraging approach. J Theor Biol 139:437-449

Submitted: May 8, 2008; Accepted: September 30, 2008

Proofs received from author(s): December 20, 2008 